\title{
Deciduous Mandibular Second Molar with Supernumerary Roots and Root Canals Associated with Missing Mandibular Permanent Premolar
}

\author{
${ }^{1}$ Vivek Rana, ${ }^{2}$ Shabina Shafi, ${ }^{2}$ Natasha Gambhir, ${ }^{3}$ Usha Rehani \\ ${ }^{1}$ Reader, Department of Pedodontics, Subharti Dental College, Meerut, Uttar Pradesh, India \\ ${ }^{2}$ Lecturer, Department of Pedodontics, Subharti Dental College, Meerut, Uttar Pradesh, India \\ ${ }^{3}$ Ex-Professor, Department of Pedodontics, Subharti Dental College, Meerut, Uttar Pradesh, India
}

Correspondence: Vivek Rana, Reader, Department of Pedodontics, Subharti Dental College, Delhi-Haridwar Bypass Road $\mathrm{NH}-58$, Meerut-250002, Uttar Pradesh, India, e-mail: drvivekrana11@rediffmail.com

\section{ABSTRACT}

Morphological variations like additional roots and root canals in human deciduous dentition are rare. Knowledge of the morphology, variation of root and root canals of deciduous teeth are useful for successful endodontic treatment and exodontia. Presented here is a case report of the supernumerary roots and additional root canals of deciduous mandibular second molar (85) with congenitally bilateral missing of mandibular permanent second premolar (35 and 45) tooth bud.

Keywords: Supernumerary roots, Additional roots, Root canals, Deciduous teeth.

\section{INTRODUCTION}

An accurate diagnosis of the morphology of the root canal system is a prerequisite for successful root canal treatment. ${ }^{1}$ Frequently, root canals are left untreated because the clinicians fail to identify their presence, particularly in teeth that have an anatomical variations or additional root canals. ${ }^{2}$ Supernumerary root is a developmental condition and may involve any tooth.

The incidence of occurrence of three roots in deciduous second molar has been recorded to be $27.8 \% .^{3}$ Although any tooth may be congenitally missing, there is a tendency for certain teeth to be missing more frequently than others. Studies on the frequency of missing second premolar have shown this tooth to be congenitally absent in as many as $47.3 \%$ of all subjects examined. ${ }^{4}$

This report describes the presence of supernumerary root and additional root canals in deciduous mandibular second molar with congenitally missing mandibular second premolar tooth bud bilaterally.

\section{CASE REPORT}

A 10-year-old male patient reported to the Department of Pedodontics of the Subharti Dental College, Meerut, India with complaint of decayed teeth in lower right region and desired to have it extracted. The patient had no systemic disorder. Clinical evaluation revealed carious lesions associated with mandibular deciduous canine, first and second molar (83, 84, 85) (Fig. 1). Further evaluation of the opposite side revealed missing mandibular deciduous canine, first and second molar $(73,74,75)$, which he got extracted by a local dentist. A preoperative periapical radiograph of 85 confirmed the presence of extensive carious lesion with periapical abscess. Also, a possible anatomic variation was suspected in relation to 85 . To further confirm the possible variation, IOPA radiograph was taken in different angulations which confirm the presence of three roots, that is two mesial and one distal and also with missing

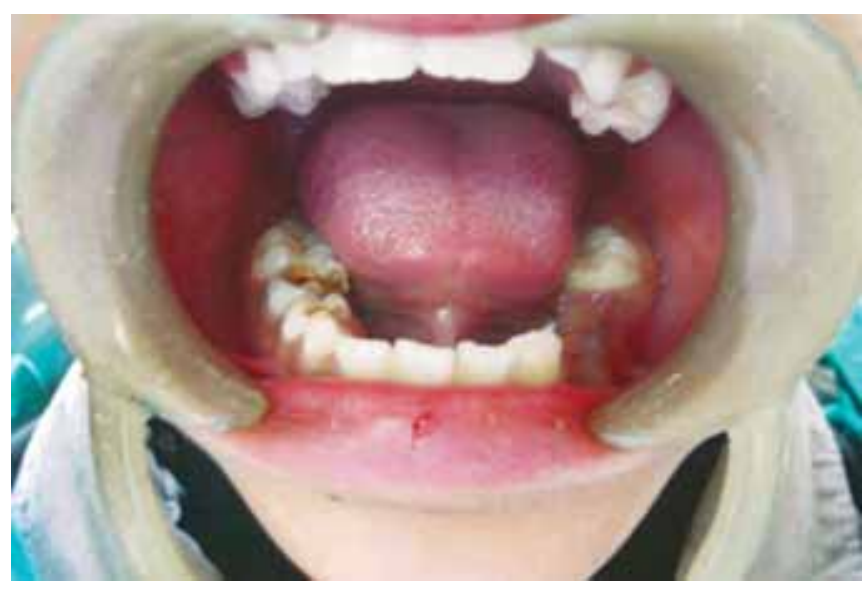

Fig. 1: Preoperative view 
premolar (45) (Fig. 2). For further confirmation of any other missing tooth, OPG was taken and revealed missing mandibular second premolar (35) (Fig. 3). The decayed mandibular deciduous second molar (85) was extracted under local anesthetic because of poor prognosis (Fig. 4). On extracted tooth, access opening was made (Fig. 5), canals were explored with size $10 \mathrm{H}$ file resulting in clinical and radiographic confirmation of 5 canals ( 3 buccal and 2 distal) (Figs 6A and B). The postextraction instructions were given to the patient and was recalled again for impression, and space analysis was done. In order to avoid space loss, lingual arch space maintainer was given (Fig.7). Mandibular

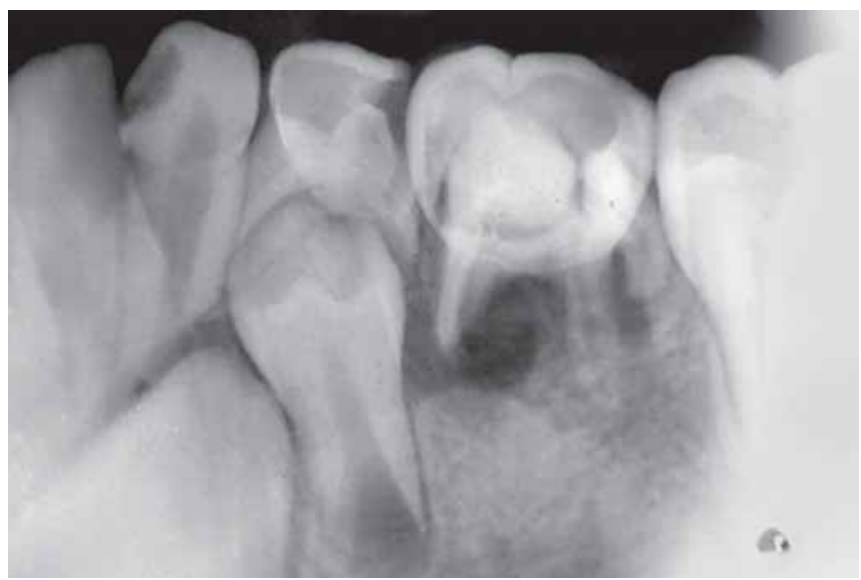

Fig. 2: IOPA X-ray showing 85 and missing 45

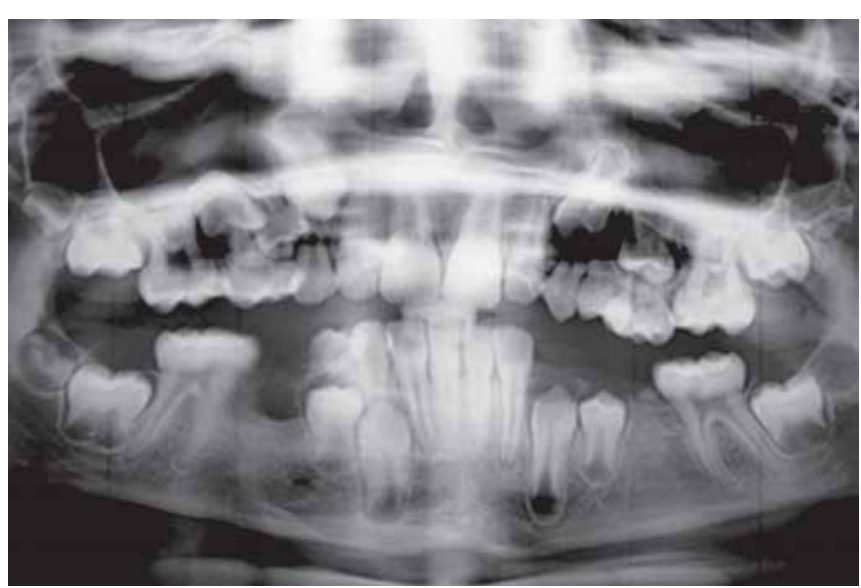

Fig. 3: OPG showing missing 35 and 45

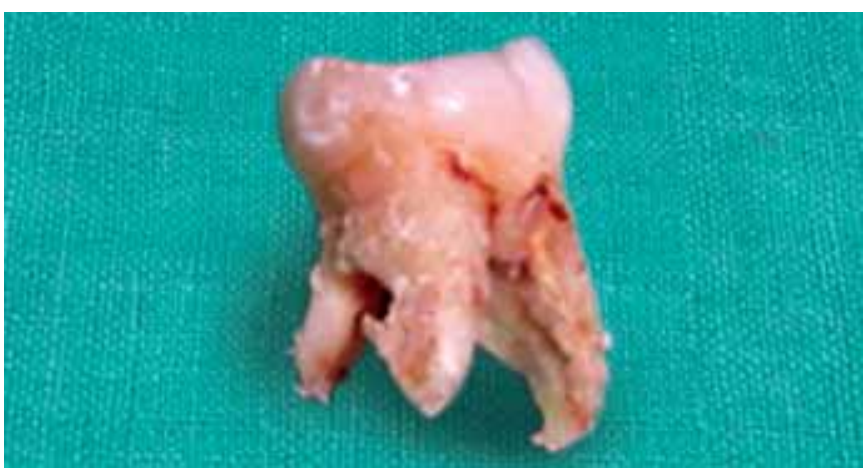

Fig. 4: Extraction of 85 with three roots deciduous canine and first molar (83 and 84) were restored with type II GIC cement.

Patient is kept under further follow-up so that later, for esthetic and functional reasons, lingual arch is replaced by removable partial denture due to missing mandibular premolars bilaterally.

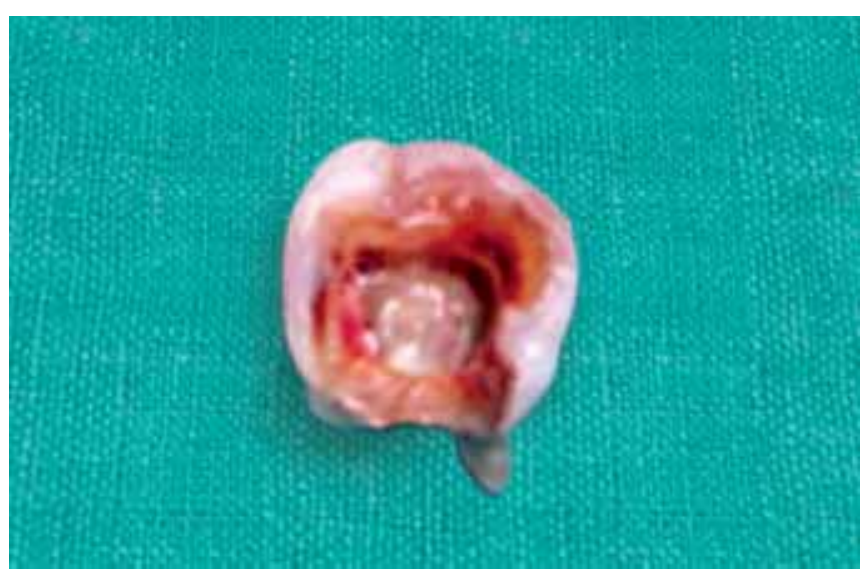

Fig. 5: Access cavity preparation done in vitro

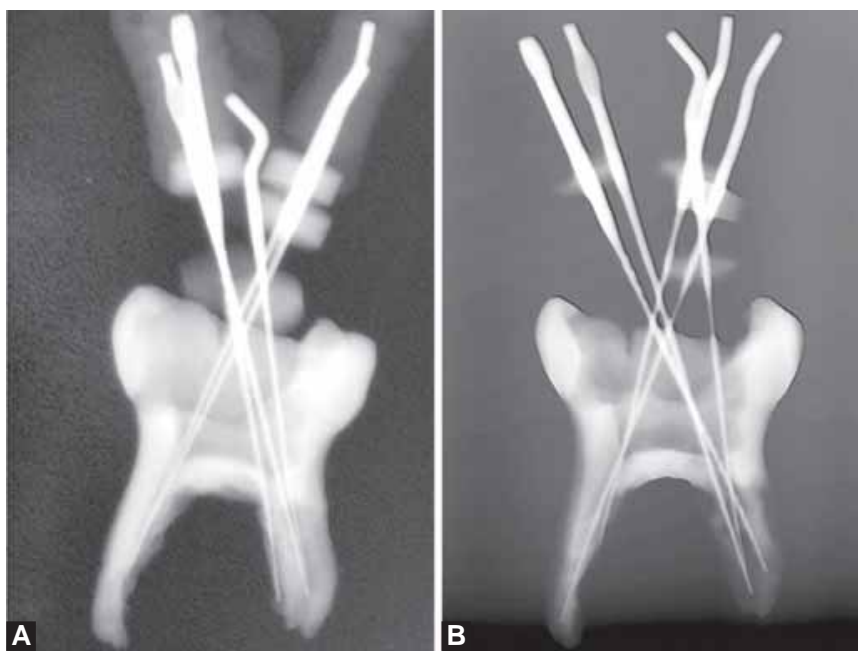

Figs 6 A and B: Radiographic view of working length with 5 root canals in vitro

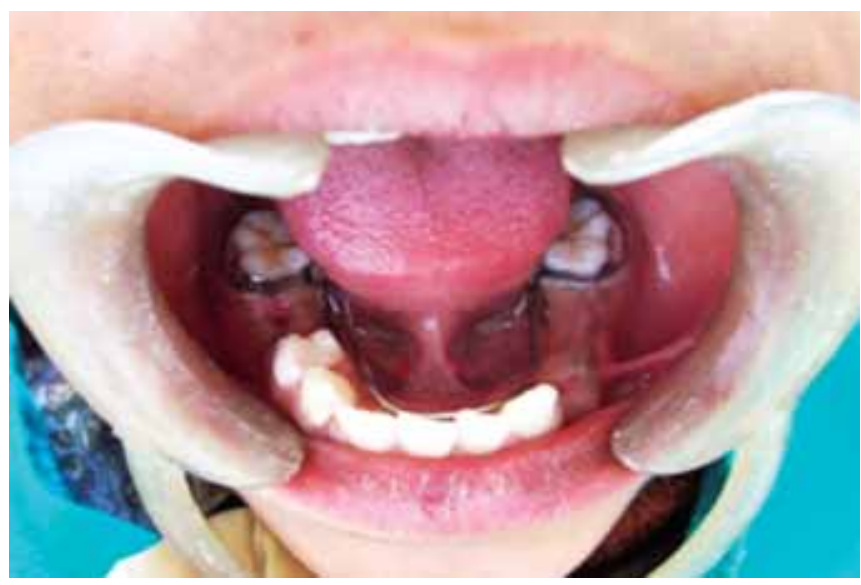

Fig. 7: Lingual arch space maintainer 


\section{DISCUSSION}

The morphology of root canals in deciduous teeth usually leads to complications in root canal therapy. Endodontic procedures for the treatment of deciduous teeth are indicated if the canals are accessible and there is an evidence of essentially normal supporting bone. ${ }^{5}$ In deciduous teeth, intimate anatomical relation of the pulp to the periodontal tissues via accessory canals result in concomitant pulpal periodontal breakdown. Deciduous mandibular second molar usually have two root (mesial and distal), but variations up to three roots have been reported. ${ }^{6,7}$ Deciduous mandibular molar have three root canals, viz. mesiobuccal, mesiolingual and distal canal. Accessory root canals in deciduous teeth were observed by Simpson, Skillen and Winter. ${ }^{8-10}$ According to Sarkar and Rao, prevalence of accessory canal in deciduous molar was less. ${ }^{11}$ Naser et al studied that all deciduous mandibular second molar have four canals: Mesiobuccal, mesiolingual, distobuccal and distolingual. ${ }^{12}$ In our case report, we found one accessory root, viz mesiolingual in deciduous mandibular second molar. In vitro access, opening of extracted deciduous mandibular second molar, we found five root canals. One additional root canal was found in mesiobuccal root and other in distal root.

Hypodontia is lack of development of one or more teeth. Although, the etiology of a single missing tooth is unknown. A familial tendency for this defect is present in many instances. Prevention of space, present in oral cavity due to missing teeth is very important because it can result in drifting of adjacent, opposing teeth and finally cause malocclusion.

\section{CONCLUSION}

The phenomenon of supernumerary roots and root canals in deciduous molar with missing permanent premolar is of considerable significance in pedodontics. Accurate knowledge of root and root canal morphology helps in endodontic treatment and extraction of teeth. Additional root may be broken off during extraction, if unrecognized and allowed to remain in the alveolus, may be the source of future infection.

\section{REFERENCES}

1. Rodig T, Hulsmann M. Diagnosis and root canal treatment of mandibular second premolar with three root canals. Int Endod J 2003;36:912-19.

2. Slowey RR. Root canal anatomy: Road map to successful endodontics. Dent clin North Am 1979;23:555-73.

3. Song JS, Kim So, Choi BJ, Choi HJ, Son HK, Lee JH. Incidence and relationship of an additional root in the mandibular first permanent molar and primary molars. Oral surgery, Oral Medicine, Oral Pathology, Oral Radiology and Endodontics 2009;107(1):e56-60.

4. Rajendran R. Developmental disturbances of oral and paraoral structures. Shafer's text book of oral pathology (6th ed). Elsevier 2009;44-46.

5. Gupta D, Grewal N. Root canal configuration of deciduous mandibular first molars an in vitro study. JISPPD 2005;23(3): 134-37.

6. Zoremchhingi, Joseph T, Varma B, Mungara J. A study of root canal morphology of human primary molars using computerized tomography: An in vitro study. JISPPD;23(1):7-12.

7. Winkler MP, Ahmad R. Multirooted anomalies in the primary dentition of native Americans. J Am Dent Assoc 1997;128: 1009-11.

8. Simpson I. An examination of root canal anatomy of primary teeth. J Canad Dent Ass 1973;9:634-40.

9. Skillan WG. Morphology of the root canal. JADA 1932; 19(5):719-35.

10. Winter GB. Abscess formation in connection with deciduous molar teeth. Arch Oral Biol 1962;7:373-79.

11. Sarkar S, Rao AP. Number of root canals, their shape, configuration, accessory root canals in radicular pulp morphology. A preliminary study. JISPPD 2002;20(3):93-97.

12. Naser A, Ramin MZ, Esrafil B. Study of root canal accessibility in human primary molars. Journal of Oral Science 2008;50(1): 69-74. 